\title{
An Improved Leaf Disc Bioassay for Detecting Calonectria pseudonaviculata in Soil and Potting Media
}

Norm Dart and Chuanxue Hong, Department of Plant Pathology, Physiology and Weed Science, Hampton Roads Agricultural Research and Extension Center, Virginia Tech, Virginia Beach 23455; and William Tyler Bradley, Virginia Polytechnic Institute and State University, Department of Statistics, Blacksburg 24061

\begin{abstract}
Dart, N., Hong, C. X., and Bradley, W. T. 2014. An improved leaf disc bioassay for detecting Calonectria pseudonaviculata in soil and potting media. Plant Dis. 98:1626-1631.

Boxwood blight caused by Calonectria pseudonaviculata results in severe defoliation and dieback to boxwood (Buxus spp.). The pathogen was first described in the United Kingdom and New Zealand in the mid to late 1990s and has since spread throughout Europe and most recently to the United States and Canada. While many Calonectria spp. have an epidemiologically significant soil phase, little is known of the role of the soil phase of $C$. pseudonaviculata in the epidemiology of boxwood blight. We optimized a leaf disc bioassay for detecting and quantifying this pathogen in soil and compared this bioassay with a standard soil plating assay originally developed for quantifying Calonectria using a Suffolk sandy-loam soil. Additionally, the sensitiv-

ity of both assays was compared among three distinct soil types (sandloam, silt-loam, and sand-peat potting media). The optimal incubation time for baiting C. pseudonaviculata from soil using the leaf disc bioassay was $96 \mathrm{~h}$. The optimal soil moisture for the bioassay was $1,000 \%$ of field capacity (flooded with 3 to $5 \mathrm{~mm}$ water). The leaf disc bioassay was able to detect $C$. pseudonaviculata at levels as low as 1 microsclerotium/g soil while the soil plating bioassay was unable to detect the pathogen below inoculum levels of 10 microsclerotia/g soil in the Suffolk sandy-loam soil. Soil type had a significant impact on the sensitivity of both assays.
\end{abstract}

Boxwood blight, caused by Calonectria pseudonaviculata (Crous et al.) L. Lombard et al. (syns. Cylindrocladium pseudonaviculatum Crous, J.Z. Groenewald \& C.F. Hill, Cylindrocladium buxicola Henricot) $(5,10)$, is a serious disease of boxwood (Buxus spp.). The disease was first described in the United Kingdom in the mid-1990s and by 2002 had spread to several other European countries and New Zealand (11). In September 2011, boxwood blight was reported for the first time in North America (14). The pathogen causes defoliation and dieback, rendering infected plants unsuitable for sale. Furthermore, severe damage also occurs in infected landscape plantings, detracting from the aesthetics of gardens $(11,14)$. In Colonial America, boxwood was planted extensively as an ornamental (1). Today, the plant remains a dominant component of historical gardens at sites such as Mount Vernon, Colonial Williamsburg, and the White House (1). Because of its cultural significance and continued popularity as an ornamental plant, boxwood remains an economically significant crop to the North American nursery and landscape industries with a wholesale value of $\$ 103$ million in the United States (14). The recent discovery of boxwood blight in North America is thus of great concern.

It is widely known that many Calonectria spp. have an epidemiologically significant soil phase $(3,9,13,15,18)$, yet relatively little research has been done to understand the potential significance of the soil phase of the boxwood blight pathogen. Results from one study suggested the ability of the pathogen to persist in decomposing leaf debris in soil for 4 years (11); results of a second study suggested the pathogen forms microsclerotia in host leaves and stems $(6,19)$. Taken together, these previous findings suggest that like other Calonectria spp., C. pseudonaviculata may have an epidemiologically significant soil phase. To further investigate the

Corresponding author: Norm Dart,

E-mail: norman.dart@vdacs.virginia.gov

Accepted for publication 17 June 2014.

http://dx.doi.org/10.1094/PDIS-03-14-0233-RE

(c) 2014 The American Phytopathological Society biology of boxwood blight in soil, it will be essential for researchers to detect and quantify the pathogen in soil.

Methods used for quantifying Calonectria spp. in soil have predominantly used soil sieving coupled with plating or direct soil plating $(9,12,13,17)$. Soil sieving is labor intensive and some soil plating techniques require the use of complex media $(8,9,17)$. Additionally, soil plating is not effective at detecting or quantifying Calonectria spp. at low inoculum levels $(8,9)$. However, leaf bioassays have been shown to detect Calonectria spp. at very low inoculum levels (8).

Leaf bioassays using whole leaves and leaf discs (soil leaf baiting) have been used to detect Calonectria spp. in soil $(8,13,16)$ Baiting Calonectria spp. from soil does not require complex media and is less labor intensive than soil sieving. Additionally, leaf bioassays can be readily adapted by growers and regulators with minimal equipment or training. One study demonstrated the use of leaf disc bioassays to quantify $C$. scoparia in artificially inoculated steam-pasteurized soil (8). To our knowledge, however, leaf bioassays have not been tested as a semi-quantitative tool in unpasteurized soil or on other Calonectria spp. Furthermore, this method has not been directly compared with soil plating. The objectives of this study were to (i) optimize the leaf disc bioassay for C. pseudonaviculata by determining the optimal soil moisture and incubation time for maximum recovery of the pathogen, (ii) compare the sensitivity and effectiveness of the leaf disc bioassay with a standard soil plating assay originally developed for quantifying Calonectria spp. over a broad range of inoculum concentrations, and (iii) compare the sensitivity and effectiveness of both assays in detecting the pathogen in three distinct soil types.

\section{Materials and Methods}

Soil, isolate collection, and microsclerotia harvesting. A Suffolk sandy-loam ( $\mathrm{pH}$ 6.0) and Codorus silt-loam ( $\mathrm{pH}$ 5.5) were collected from two boxwood nurseries located in the Coastal Plains and Blue Ridge Mountains of Virginia, respectively. Both nurseries had no known history of boxwood blight and were assayed for $C$. pseudonaviculata using the bioassay and soil plating assays described below and the pathogen was not detected. The soil was stored at 22 to $27^{\circ} \mathrm{C}$ in 18.9-liter plastic buckets for up to 6 months. 
Prior to use, soils were sifted through an $850-\mu \mathrm{m}$ sieve and mixed by hand. A single-conidium isolate of $C$. pseudonaviculata was obtained from an infected boxwood plant (Buxus sempervirens 'Arborescens') at a nursery in Carroll County, VA, and used in this study.

Microsclerotia of $C$. pseudonaviculata were obtained by growing the fungus on potato dextrose agar for 6 to 8 weeks. Colonized agar was then blended in a laboratory blender for $1 \mathrm{~min}$ at low speed with distilled water. The slurry of mycelium, conidia, and microsclerotia was poured through nested sieves of 850, 250, and $142 \mu \mathrm{m}$ pore size. The materials on the 250 and $142 \mu \mathrm{m}$ sieves were washed under tap water to remove fragments of mycelia and conidia. Microsclerotia from both sieves were blended again for 1 min at low speed, poured through a $38-\mu \mathrm{m}$ sieve, and rinsed again with tap water. The microsclerotia were suspended in $250 \mathrm{ml}$ distilled water by constant mixing with a metal stirring bar. The microsclerotia were enumerated by pipetting $100 \mu \mathrm{l}$ of suspended microsclerotia onto an inverted petri dish cover and counted with the aid of a stereomicroscope. Microsclerotia used for experiments were determined to be $100 \%$ viable by counting the proportion of microsclerotia that germinated on acidified peptone-dextrose-agar (PEDA) after 10 days $(8,12,15)$.

Effect of soil moisture. The field capacity $(-33 \mathrm{kPa})$ of the Suffolk sandy-loam soil was determined by inserting a tensiometer (Irrometer, Riverside, CA) into a 2,000-ml beaker filled with soil and slowly adding water over a 48-h period until reaching field capacity. Soil at field capacity $(50 \mathrm{~g})$ was then dried by microwaving on high power for $10 \mathrm{~min}$ and the gravimetric water content was calculated (ww/dw). One kilogram of Suffolk sandy-loam soil (dw) was mixed with required volumes of suspended microsclerotia to make a final density of 0 and $50 / \mathrm{g}$. Twenty-five grams of soil was placed into $15 \times 100 \mathrm{~mm}$ petri dishes and adjusted to 50,100, $150,200,300,500$, and $1,000 \%$ field capacity by adding required volumes of distilled water with a 1-ml pipette. Soil in each moisture treatment was baited using a bioassay with 10 to 20 boxwood leaf discs $(6 \mathrm{~mm}$ diameter) placed flat and equidistantly on the surface of soil in each petri dish for $96 \mathrm{~h}$ at 23 to $25^{\circ} \mathrm{C}$ (Fig. 1). At $1,000 \%$ field capacity, the soil was flooded with 3 to $5 \mathrm{~mm}$ water so the leaf discs floated on top of the water. After incubation with soil, leaf discs were then surface-sterilized in $0.25 \% \mathrm{NaOCl}$ for 30 $\mathrm{s}$, rinsed under a stream of water for $30 \mathrm{~s}$, and plated onto PEDA. Isolation plates were incubated at 23 to $25^{\circ} \mathrm{C}$ for 7 to 10 days, at which time individual baits were evaluated for sporulation by $C$. pseudonaviculata. A leaf disc was considered infected by $C$. pseudonaviculata if pathogen sporulation was observed. Proportions of leaf discs infected were plotted against microsclerotial density to establish a dose-infection response relationship. Three replicates were used and each experiment was repeated once for this and each experiment described below.

Baiting time optimization. Suffolk sandy-loam soil was mixed with microsclerotia to make a final density of 50/g and adjusted to $1,000 \%$ field capacity. For each treatment, $100 \mathrm{~g}$ of soil (dw) was placed in a 500-ml plastic container. At least 100 leaf discs were placed approximately equidistantly across the soil surface within 2 $\mathrm{h}$ after inoculation. Twenty arbitrarily chosen leaf discs were removed after 24, 48, 72, 96, and $120 \mathrm{~h}$ incubation. Following the initial incubation, leaf discs were processed and evaluated for infection by $C$. pseudonaviculata as described above. Proportions of infected leaf discs were recorded and plotted against time to establish a time-infection response relationship.

Comparing baiting assay with soil plating. Suffolk sandyloam soil was artificially inoculated with microsclerotia at $0,1,5$, 10,25 , and $50 / \mathrm{g}(\mathrm{dw})$ by mixing the required volume of suspended microsclerotia into $200 \mathrm{~g}(\mathrm{dw})$ soil. Inoculated soil was processed by soil plating (12) and the leaf disc bioassay within 7 days of inoculation. For soil plating, $25 \mathrm{~g}(\mathrm{dw})$ of inoculated soil was blended with $250 \mathrm{ml}$ water at low speed for $1 \mathrm{~min}$ and the suspension was poured through a $38-\mu \mathrm{m}$ sieve and rinsed for $5 \mathrm{~min}$ with tap water to remove most fine silt and clay. The filtrate was then mixed with $50 \mathrm{ml}$ water, and three aliquots of $1 \mathrm{ml}$ of suspension was plated onto three separate PEDA plates. For the bioassay, $25 \mathrm{~g}$ (dw) inoculated soil was placed in petri dishes and baited with leaf discs as described above. Leaf discs of $B$. sempervirens 'Arborescens' and azalea (Rhododendron sp.) were evaluated as baits. Treatments were incubated at 23 to $25^{\circ} \mathrm{C}$ for $96 \mathrm{~h}$ at moisture levels of 300 and $1,000 \%$ of field capacity. Moisture levels were determined and adjusted as described above. Leaf discs were removed from soil, surface-sterilized, and plated on PEDA. Both the soil and bioassay plates were incubated at 23 to $25^{\circ} \mathrm{C}$ for 7 to 10 days, at which time they were evaluated with a stereomicroscope. Colony forming units (CFUs) and sporulation of C. pseudonaviculata from leaf discs was identified based on conidial and vesicle morphology (5). Proportions of infected leaf discs and number of CFUs were recorded.

Evaluating baiting assay and direct plating with field soil samples. Five soil samples were collected from two production nurseries (the Chapel and Lynx Farms), and one residential landscape (Chapel home). All sites were located in Carroll County, VA, within a $2 \mathrm{~km}$ radius and had a silt-loam texture. At each site, $C$. pseudonaviculata had been previously isolated from boxwood and the soil $(6,19)$. Each sample weighed approximately $3 \mathrm{~kg}$ and consisted of at least 25 subsamples collected from the O- or A-horizon. The O-horizon at each site consisted of a thin layer of fallen boxwood leaves and other decomposing weed debris (less than $2 \mathrm{~cm}$ ). Soil was collected from the top $4 \mathrm{~cm}$ of the A-horizon. The $\mathrm{pH}$ of the soil from A-horizons collected ranged from 5.5 to 6. Each composite sample was sifted, mixed, and stored as described above. Each soil sample was processed using soil plating and the leaf disc bioassay as described above. For the bioassay, soil moisture was adjusted to $1,000 \%$ field capacity and $B$. sempervirens "Arborescens' leaf discs were used for this and all experiments below.

Effect of soil type. The Suffolk sandy-loam, Codorus silt-loam, and a potting mix (peat-coarse sand, 1:1) were infested with relatively high, medium, and low levels of microsclerotia at 25, 15, and $5 / \mathrm{g}$, respectively. A noninoculated treatment was included for each soil type as a control. Inoculated soil samples were processed using soil baiting and plating as described above. The bioassay was tested on each soil type and microsclerotia level at $1,000 \%$ field capacity. Each treatment used $25 \mathrm{~g}$ soil (dw) in petri plates.

Statistical analysis. Descriptive statistics were calculated, summarized, and graphed using Microsoft Excel. Further analysis was

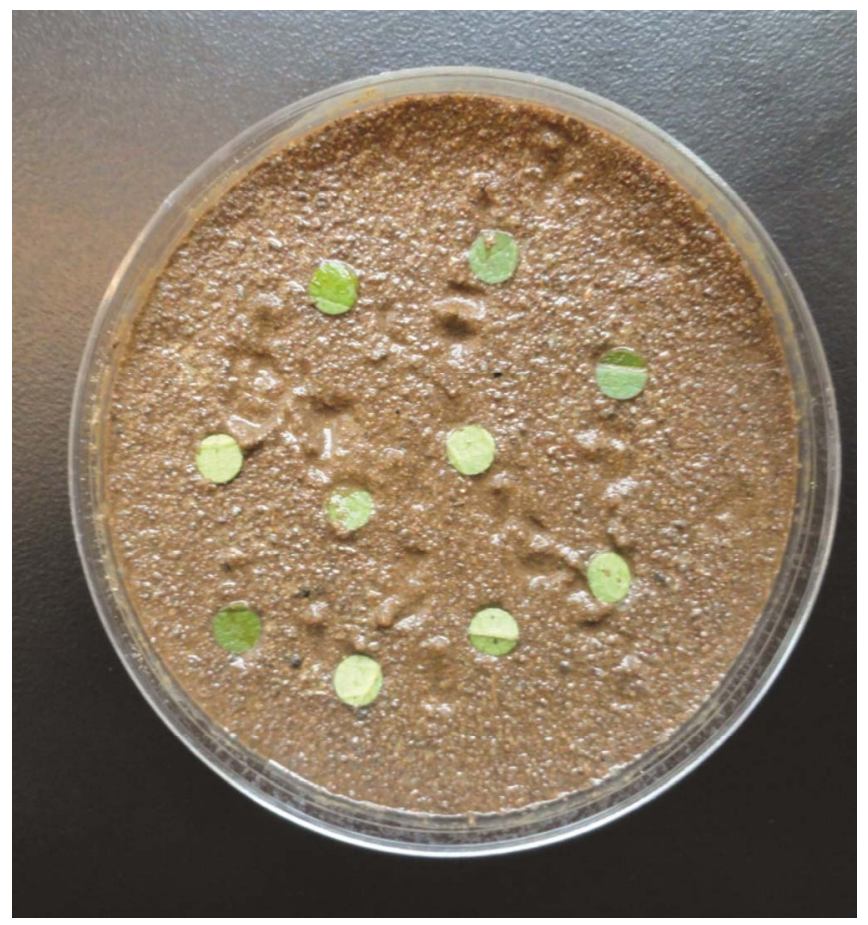

Fig. 1. Bioassay with leaf discs placed flat on the surface of soil in petri dish. Leaf discs are incubated for $96 \mathrm{~h}$ at 23 to $25^{\circ} \mathrm{C}$ 
performed and graphed using the $\mathrm{R}$ statistical platform version 3.0.1 (R Foundation for Statistical Computing, Vienna, Austria). Data from repeated experiments measuring the effect of soil type were analyzed using logistic regression for the soil baiting and zero-inflated Poisson for soil plating. These methods were chosen over other analyses because of the non-normal distribution of the data. Because the soil baiting has a specific number of leaf discs per petri dish and each individual leaf disc has a binary outcome of either infection or no infection, the number of infected leaf discs follows a binomial distribution. Therefore, logistic regression is appropriate. The GLM function in R was used to fit the model. Hosmer-Lemeshow Goodness of Fit Test was utilized for diagnostics with no significant result, implying this is the correct model. The soil plating method uses count data, indicating a Poisson model would be a good choice. However, the means and standard deviations of the grouped data do not match, a trait assumed under a Poisson model, and a large number of zeros exist. A zero-inflated Poisson model was then fit using the zeroinfl method under the \{pscl\} package in R. This model was compared to the standard Poisson model and found to be significantly better.

\section{Results}

Effect of soil moisture. The field capacity of the Suffolk sandyloam was determined to be $10 \%$ (ww/dw). The soil treatments were thus adjusted to soil moisture levels of $5,10,15,20,30,50$, and $100 \%$ (ww/dw) to correspond to $50,100,150,200,300,500$, and $1,000 \%$ of field capacity.

A greater proportion of leaf discs became infected by $C$. pseudonaviculata at higher soil moisture levels. The proportion of infected leaves increased with increasing soil moisture from 50 to

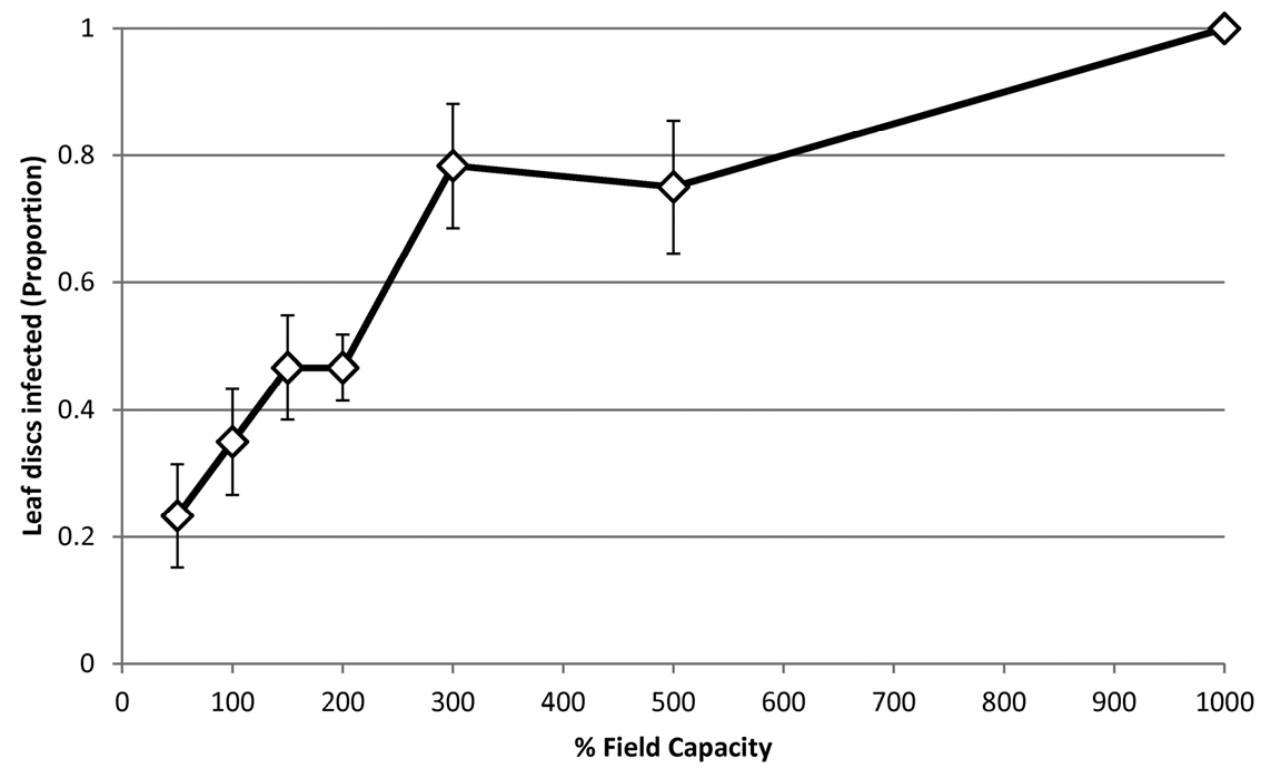

Fig. 2. Proportion of leaf discs infected by Calonectria pseudonaviculata over a range of soil moisture levels (measured as $\%$ of field capacity). Leaf discs were incubated with a Suffolk sandy-loam soil infested with microsclerotia $(25 / \mathrm{g} \mathrm{dw})$ for $96 \mathrm{~h}$. Error bars show standard deviation of two replicate experiments with three replicates within an experiment.

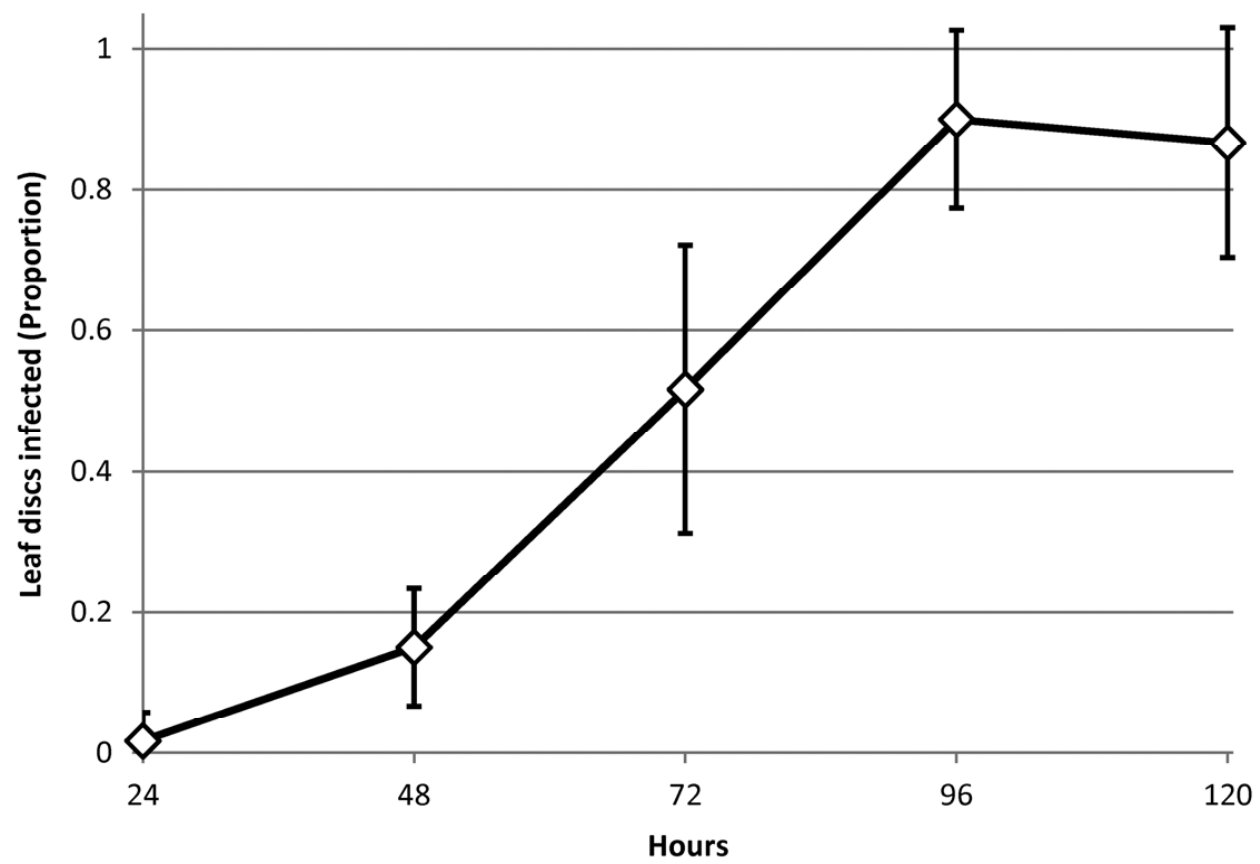

Fig. 3. Proportion of leaf discs infected by Calonectria pseudonaviculata plotted against time. Leaf discs were incubated with a Suffolk sandy-loam soil inoculated with microsclerotia $(50 / \mathrm{g} \mathrm{dw})$ for up to 5 days and harvested every $24 \mathrm{~h}$. Error bars show standard deviation of two replicate experiments with three replicates within an experiment. 
$300 \%$ field capacity, and then increased at a slower rate, reaching $100 \%$ colonization at $1,000 \%$ field capacity (Fig. 2). No Calonectria species was detected in noninoculated soil samples in this or the other experiments described below.

Baiting time optimization. The highest proportions of colonized leaf discs were observed at $96 \mathrm{~h}$ of incubation (Fig. 3). Leaf discs incubated for more than $96 \mathrm{~h}$ were frequently overgrown with other soil fungi and the presence of $C$. pseudonaviculata was harder to discern visually. Additionally, leaf discs incubated for longer than $96 \mathrm{~h}$ were at advanced stages of decomposition and tended to fall apart during removal from the soil.

Comparing baiting bioassay with soil plating. For both the bioassay and soil plating techniques, the proportion of colonized leaf discs and CFUs were positively correlated when plotted against the microsclerotial levels in artificially infested unpasteurized soil (Fig. 4). A strong correlation was observed between the number of leaf discs infected and the concentration of microsclerotia in the soil at microsclerotia levels below 10/g at 1,000\% field capacity (Fig. 4). The leaf disc assay was thus quantitative at lower microsclerotia concentrations. At higher concentrations of microsclerotia, infection rates of the leaf discs became saturated and the leaf disc assay was not a quantitative assay. In comparison, the soil plating was a quantitative assay at higher microsclerotia levels (above 10/g) but could not detect or distinguish levels of microsclerotia at lower concentrations. Boxwood leaf discs were more
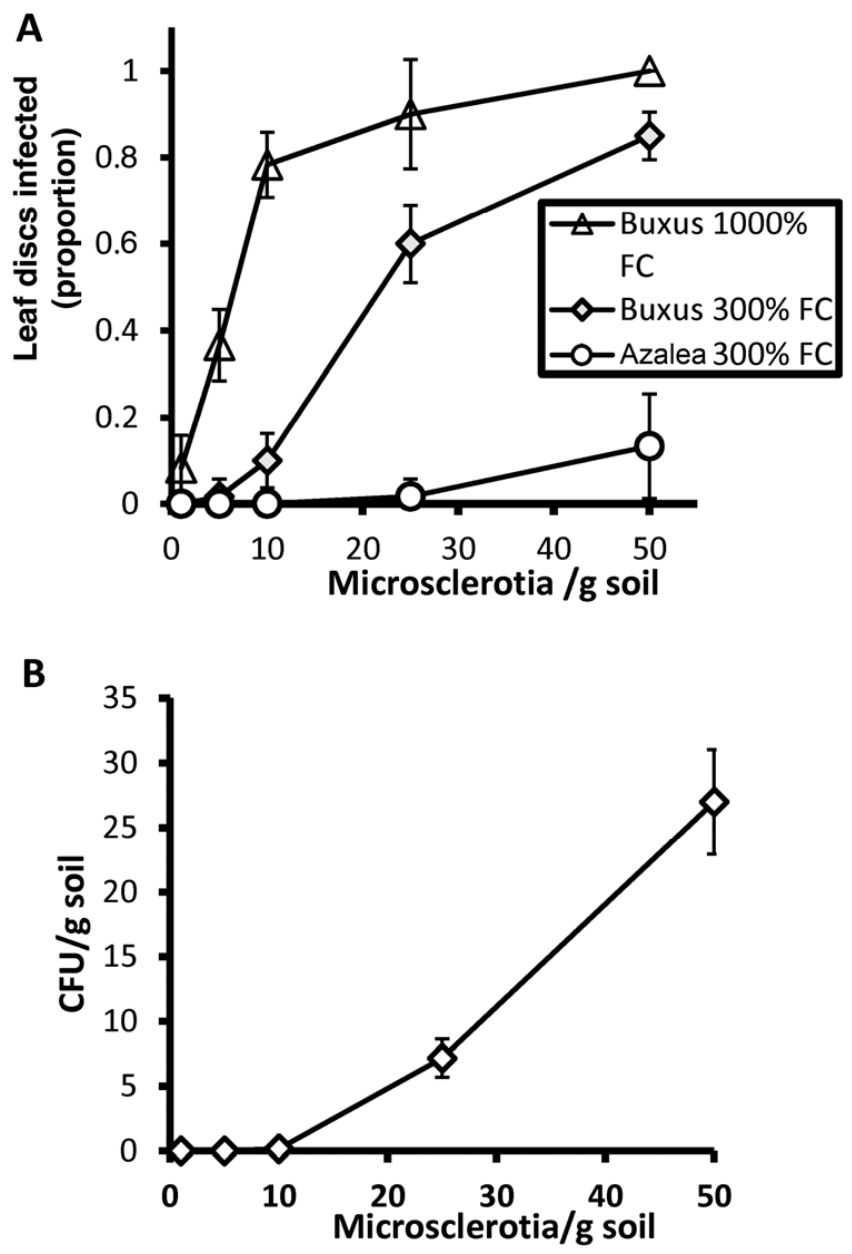

Fig. 4. (A) Proportion of leaf discs infected with Calonectria pseudonaviculata after incubating discs in artificially inoculated Suffolk sandy-loam soil plotted against inoculum concentration. The bioassay was carried out at $300 \%$ and $1,000 \%$ of field capacity (FC) using boxwood (Buxus sempervirens 'Arborescens') and azalea (Rhododendron $\mathrm{sp}$.) leaf discs. (B) CFUs/g soil recovered from artificially inoculated Suffolk sandy-loam soil plotted against inoculum concentration. Error bars show standard deviation of two replicate experiments with three replicates within an experiment. effective at detecting lower propagule densities than azalea leaf discs using the bioassay (Fig. 4A). Boxwood leaf discs were able to detect $C$. pseudonaviculata at microsclerotial densities as low as 5/g soil while azalea leaf discs detected propagule densities down to $25 / \mathrm{g}$ soil when incubated at $300 \%$ field capacity. Increasing soil moisture from 300 to $1,000 \%$ of field capacity brought the detection sensitivity of the boxwood leaf disc bioassay from 5 to 1 microsclerotia/g soil.

Overall the boxwood leaf disc bioassay was able to detect $C$. pseudonaviculata at lower propagule densities than soil plating when processing the same amount of soil for each protocol. The bioassay was able to detect $C$. pseudonaviculata as low as 1 microsclerotium/g when incubated at $1,000 \%$ field capacity while soil plating recovered $C$. pseudonaviculata only down to 10 microsclerotia/g soil (Fig. 4B).

Evaluating leaf disc bioassay and direct plating with field samples. The bioassay and plating were able to detect $C$. pseudonaviculata in naturally infested soil samples from areas where the pathogen was present. Soil plating detected C. pseudonaviculata in three of five soil samples and the bioassay detected the pathogen in 4 of 5 tested samples (Table 1).

Effect of soil type. For the bioassay, significantly fewer leaf discs were infected in the sand-peat potting mix compared to the other two soil types at the highest microsclerotial level based on logistic regression analysis $(P<0.05)$ (Fig. 5). No statistical differences were observed among soil types at any of the other microsclerotial densities for the bioassay. For the soil plating, the inoculated sand-peat potting mix and Codorus silt-loam had significantly fewer CFUs in comparison to the Suffolk sandy-loam at all three microsclerotial levels based on zero-inflated Poisson analysis $(P<$ 0.05) (Fig. 6).

\section{Discussion}

This study improved a leaf disc bioassay for detecting and quantifying $C$. pseudonaviculata in soil and soilless media at low concentrations. This tool provides a convenient and affordable means for diagnosticians and researchers to monitor for and measure the presence of the pathogen in soil.

C. pseudonaviculata was more effectively baited from soil using boxwood leaf discs when compared to azalea leaf discs. Gonçalves et al. showed that Calonectria scoparia can be baited from soil using eucalyptus, geranium, and azalea leaf discs with similar efficiency as we were able to bait $C$. pseudonaviculata using boxwood leaf discs (8). C. scoparia is known to infect hosts from numerous plant families (4), while $C$. pseudonaviculata is thought to only infect plants in the Buxaceae family (11). Host recognition factors that drive host specificity in living plants may explain the apparent preference of $C$. pseudonaviculata for boxwood over azalea leaf discs in soil.

By increasing soil moisture to $1,000 \%$ of field capacity and incubating leaf discs for $96 \mathrm{~h}$, we further optimized the sensitivity of the bioassay for detecting C. pseudonaviculata in soil. Hwang and Ko reported optimal recovery of $C$. crotalariae from soil at 48 $\mathrm{h}$ incubation using papaya stems; however, they used higher inoculum concentrations than those used in this study (13). Gonçalves et al. reported $96 \mathrm{~h}$ as the optimal incubation time when using azalea leaf disc to bait $C$. scoparia from soil using inoculum concentra-

Table 1. The average number of CFUs and proportion of leaf discs infected from 5 soil samples naturally infested with Calonectria pseudonaviculata

\begin{tabular}{lcc}
\hline Site & Soil plating $^{\mathbf{a}}$ & Leaf disc bioassay $^{\mathbf{b}}$ \\
\hline Chapel nursery O-horizon & 0.50 & 0.05 \\
Chapel home O-horizon & 8.30 & 0.25 \\
Chapel home A-horizon & 0.00 & 0.02 \\
Lynx farm tilled 1 & 3.33 & 0.03 \\
Lynx farm tilled 2 & 0.00 & 0.00 \\
\hline
\end{tabular}

${ }^{a}$ Average CFUs per petri dish of three replicated experiments.

bAverage proportion infected leaf discs per petri dish of three replicated experiments. 
tions similar to those used in this study (8). Gonçalves et al. found that by increasing soil moisture from 33 to $165 \%$ field capacity, they increased colonization of azalea leaf discs by $C$. scoparia in artificially infested pasteurized soil (8). We found by further increasing soil moisture to $1,000 \%$ field capacity, we were able to enhance the sensitivity of the leaf disc bioassay when baiting for $C$. pseudonaviculata. Soil at $1,000 \%$ field capacity contains so much water that the soil is actually covered with 3 to $5 \mathrm{~mm}$ of water. During this study, conidia were frequently observed being produced directly from microsclerotia. We speculate that the conidia produced by microsclerotia float and concentrate at surface of the water in flooded plates, resulting in the higher sensitivity of the leaf disc bioassay at $1,000 \%$ field capacity.

The improved bioassay was consistently more sensitive than the soil plating assay we tested. The bioassay proved effective at detecting and quantifying $C$. pseudonaviculata in artificially infested soil down to levels of 1 microsclerotium/g soil when boxwood leaf discs were used, while the soil plating only detected the pathogen at levels down to $10 \mathrm{microsclerotia/g}$ soil. When comparing the sensitivity of these assays using naturally infested soil, the boxwood leaf disc bioassay detected C. pseudonaviculata in $80 \%$ of the soil samples while soil plating only detected the pathogen in $60 \%$. These results are consistent with observations of previous authors that suggested soil plating may not be effective at detecting Calonectria spp. at relatively low inoculum levels $(8,9)$. While the bioassay was more sensitive than the soil plating assay tested in this study, the bioassay was only an effective quantitative assay at microsclerotia concentrations under $10 / \mathrm{g}$, while the soil plating was only able to detected the pathogen and serve as a quantitative assay at concentrations above $10 / \mathrm{g}$. This suggests that the bioassay

Data from two replicate experiments with three replicates within an experiment
Suffolk High

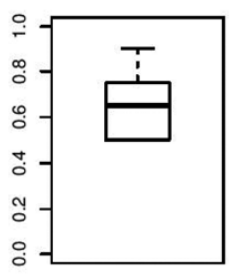

Suffolk Medium

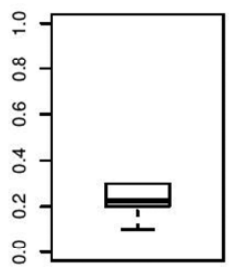

Suffolk Low

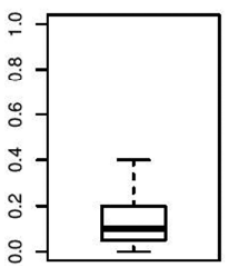

Codorus High

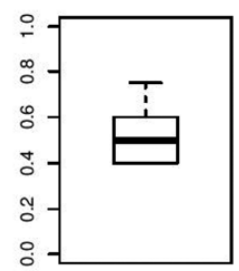

Codorus Medium

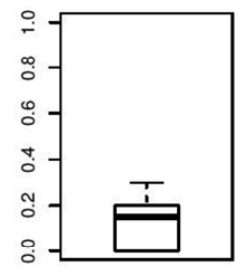

Codorus Low

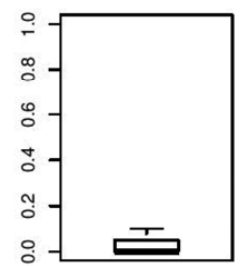

Peat-sand High

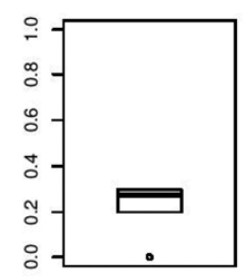

Peat-sand Medium

Peat-sand Low

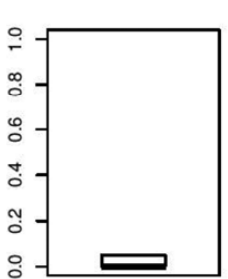

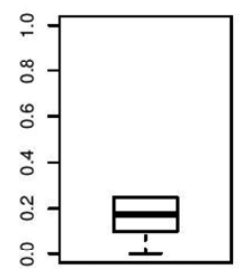

Fig. 5. Boxplots comparing the proportion of leaf discs infected with Calonectria pseudonaviculata after incubating in three artificially inoculated soil/medium types (Suffolk sandy-loam, Codorus silt-loam, and a peat-sand potting media). Each soil was inoculated with 25 (high), 15 (medium), and 5 microsclerotia/g (low), respectively. Significantly fewer leaf discs were infected in the sand-peat potting mix compared to the other two soil types at the highest microsclerotia level $(P<0.05)$ using logistical regression analysis in $\mathrm{R}$. will be a useful tool for quantifying and comparing lower microsclerotia concentrations, while plating may provide a better quantitative measure at higher microsclerotia concentrations. The appropriate test will thus depend on the concentration of microsclerotia in the soil when a quantitative measure is needed, but for detection alone, the bioassay consistently provides the highest sensitivity. Other methods of quantifying microsclerotia in soil have been developed, such as elutriation coupled with plating (17), that were not tested or compared to the soil bioassay. These methods are more time consuming than direct plating and soil bioassays and can require specialized equipment, but could provide different sensitivity than the soil plating tested in this paper. This paper compared a soil bioassay with the most basic and standard form of soil plating.

Soil type had a significant effect on the measure of C. pseudonaviculata populations when using soil plating, while the effect of soil was somewhat mitigated when using the bioassay. The artificially infested peat-sand potting mix and Codorus silt-loam were significantly lower in CFUs than the Suffolk sandy-loam at the high, medium, and low microsclerotial levels when using the soil plating technique. For the bioassay, there was a statistically significant lower proportion of infected leaf discs observed in the artificially infested peat-sand potting mix compared to the Codorus siltloam and Suffolk sandy-loam at the highest microsclerotia level.

One hypothesis that may explain the lower number of CFUs plated from the peat-sand potting mix and Codorus silt-loam may be the suppression of microsclerotial germination by microbial communities. Soil type is known to affect soil microbial diversity and biomass (7). Peat and silt soils tend to have more soil organic

Data from two replicate experiments with three replicates within an experiment
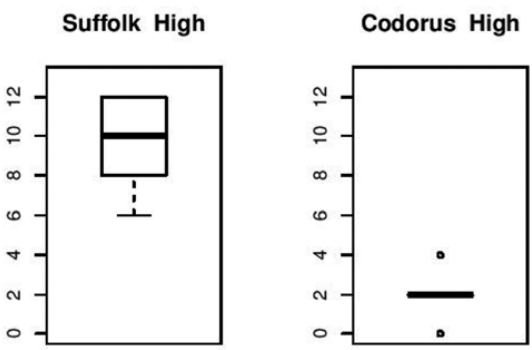

Peat High

Suffolk Med

Codorus Med
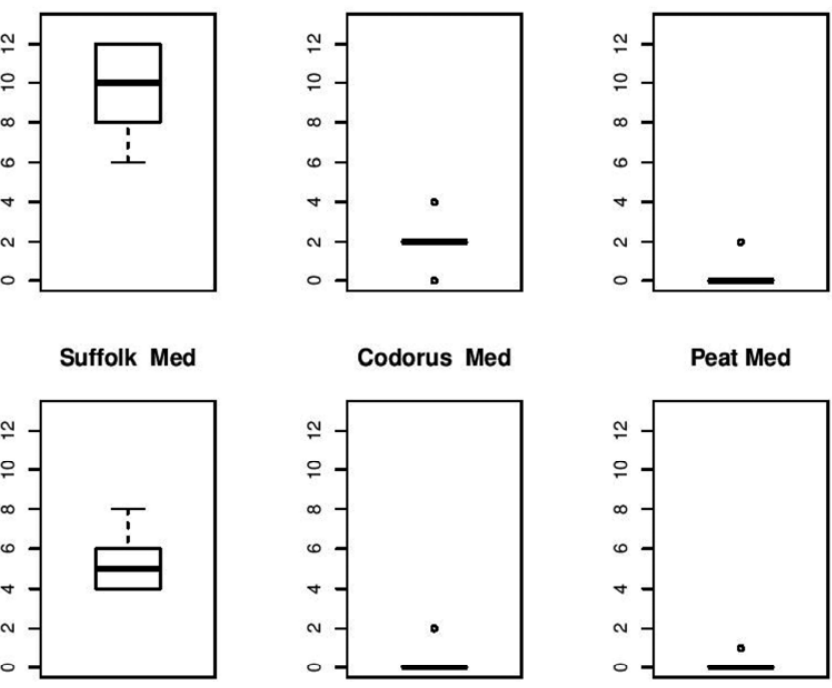

Peat Med

Suffolk Low

Codorus Low
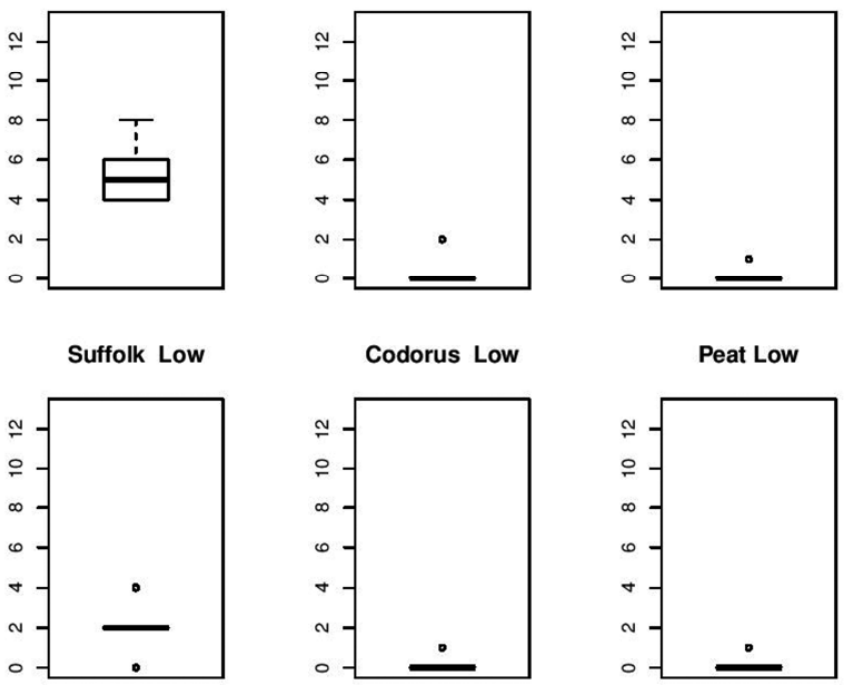

Peat Low

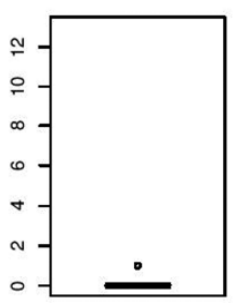

Fig. 6. Boxplots comparing the CFUs of Calonectria pseudonaviculata recovered from soil at high, medium, and low microsclerotia levels. The sand-peat potting mix and Codorus silt-loam had significantly fewer CFUs in comparison to the Suffolk sandy-loam at all three microsclerotial levels $(P<0.05)$ using zero-inflated Poisson regression analysis in $\mathrm{R}$. 
matter than sandy soil, which may increase populations of microbes associated with disease suppression (7). The bioassay uses leaf discs with open wounds that exude plant sap. The plant sap may actively stimulate microsclerotial germination (8), allowing the bioassay to maintain effectiveness in soils with relatively high levels of competitive or suppressive microorganisms. Black and Beute (2) found that soils with higher populations of actinomycetes had lower incidence of black rot of peanut caused by Calonectria ilicicola. While it was not determined if the actinomycetes suppressed microsclerotia germination, this could be a potential mechanism that resulted in the lower disease incidence. Other factors that could contribute to differences in microsclerotia germination could be differences in soil $\mathrm{pH}$, salinity, mineralogy, or bulk density. Future work should be conducted to determine if germination of microsclerotia is suppressed in certain soils and, if so, what mechanisms are involved. Regardless of the underlying mechanism, our results show that soil type affects the ability to recover and detect the boxwood blight pathogen from soil. Therefore, researchers and diagnosticians must exercise caution when comparing populations or interpreting presence/absence data of $C$. pseudonaviculata from various soil and potting medium types.

\section{Acknowledgments}

This research was supported in part by a grant of Farm Bill 2013 from USDA Animal and Plant Health Inspection Service - Center for Plant Health Science and Technology (Agreement \# 13-8130-0282-CA). We thank Drs. Anton Baudoin, Boris Vinatzer, and Chuck Johnson for critical review of this manuscript before submission.

\section{Literature Cited}

1. Batdorf, L. N. 2005. History of the boxwood. Pages 8-9 in: Boxwood Handbook. The American Boxwood Society, Boyce, VA.

2. Black, M. C., and Beute, M. K. 1985. Soil components that affect the severity of Cylindrocladium black rot on peanuts. Plant Dis. 69:36-39.

3. Crous, W. P. 2002. Pathogenicity and Microsclerotia. Pages 8-12 in: Taxonomy and pathology of Cylindrocladium and allied genera. American Phytopathological Society, St. Paul, MN.

4. Crous, P. W., Alfenas, A. C., and Wingfield, M. J. 1993. Calonectria scoparia and Calonectria morganii sp. nov., and variation among isolates of their Cylindrocladium anamorphs. Mycol. Res. 97:701-708.
5. Crous, W. P., Groenewald, J. Z., and Hill, C. F. 2002. Cylindrocladium pseudonaviculatum sp. nov. from New Zealand, and new Cylindrocladium records from Vietnam. Sydowia 54:23-34.

6. Dart, N. L., Arrington, S. M., and Weeda, S. M. 2012. Flaming to reduce inocula of the boxwood blight pathogen, Cylindrocladium pseudonaviculatum in field soil. Online. Plant Health Progress. DOI:10.1094/PHP-20121026-01-BR

7. Garbeva, P., Van Veen, J. A., and Van Elsas, J. D. 2004. Microbial diversity in soil: Selection of microbial populations by plant and soil type and implications for disease suppressiveness. Annu. Rev. Phytopathol. 42:243-270.

8. Gonçalves, R. C., Alfenas, A. C., Maffia, L. A., and Crous, P. W. 2001 Evaluation of bioassays to quantify Cylindrocladium inocula in soil. Mycoscience 42:261-264

9. Griffin, G. J. 1977. Improved selective medium for isolating Cylindrocladium crotalariae microsclerotia from naturally infested soils. Can. J. Microbiol. 23:680-683.

10. Henricot, B., and Culmam, A. 2002. Cylindrocladium buxicola, a new species affecting Buxus spp, and its phylogenetic status. Mycologia 94:980997.

11. Henricot, B., Gorton, C., Denton, G., and Denton, J. 2008. Studies on the control of Cylindrocladium buxicola using fungicides and host resistance. Plant Dis. 92:1273-1279.

12. Hwang, S. C., and Ko, W. H. 1975. A medium for enumeration and isolation of Calonectria crotalariae from soil. Phytopathology 65:1036-1037.

13. Hwang, S. C., and Ko, W. H. 1976. Biology of conidia, ascospores, and microsclerotia of Calonectria crotalariae in soil. Phytopathology 66:51-54.

14. Ivors, K. L., Lacey, L. W., Milks, D. C., Douglas, S. M., Inman, M. K., Marra, R. E., and LaMondia, J. A. 2012. First report of boxwood blight caused by Cylindrocladium pseudonaviculatum in the United States. Plant Dis. 96:1070

15. Kuruppu, P. U., Schneider, R. W., and Russin, J. S. 2004. Effects of temperature on microsclerotia of Calonectria ilicicola and soybean root colonization by this fungus. Plant Dis. 88:620-624.

16. Linderman, R. G. 1972. Isolation of Cylindrocladium from soil or infected azalea stems with azalea leaf traps. Phytopathology 62:736-739.

17. Phipps, P. M., Beute, M. K., and Barker, K. R. 1976. An elutriation method for quantitative isolation of Cylindrocladium crotalariae microsclerotia from peanut field soil. Phytopathology 66:1255-1259.

18. Thies, W. G., and Patton, R. F. 1970. The biology of Cylindrocladium scoparium in Wisconsin forest tree nurseries. Phytopathology 60:1662-1668.

19. Weeda, S. M., and Dart, N. L. 2012. Histological evidence that microsclerotia play a significant role in disease cycle of the boxwood blight pathogen, Cylindrocladium pseudonaviculatum, in Southeastern United States and implications for disease mitigation. Online. Plant Health Progress. DOI:10.1094/PHP-2012-0403-01-BR 